\title{
Synthesis of 5-Bromouridine Oligonucleotides by the Reaction of 5-Bromouridine with Tri(imidazol-1-yl)phosphine
}

\author{
Takeo SHIMIDZU* and Kazushige YAMANA \\ Division of Molecular Engineering, Kyoto University, \\ Yoshida, Sakyo-ku, Kyoto 606, Japan
}

(Received June 6, 1983)

\begin{abstract}
Bromouridine oligonucleotides were synthesized directly from 5-bromouridine by a polycondensation method. The reaction of 5-bromouridine with tri(imidazol-1-yl)phosphine was carried out at a relatively low temperature and the subsequent in situ oxidation of the resulting phosphite oligomer was achieved with iodine and water. 5-Bromouridine oligonucleotides up to a hexamer were obtained in high yields. The phosphodiester linkage of the oligomer consists of both $3^{\prime}, 5^{\prime}$ - and $2^{\prime}, 5^{\prime}$-linkages. The interaction of 5-bromouridine oligonucleotides with poly $\mathrm{A}$ was investigated.
\end{abstract}

KEY WORDS 5-Bromouridine / Tri(imidazol-1-yl)phosphine
Polycondensation / Oligoribonucleotide / 5-Bromouridine Oligonucleotide /
Phosphodiester Linkage / Interaction of 5-Bromouridine Oliogonucleotide /

Chemical polymerization approaches to the synthesis of oligoribonucleotides are of two types: the activation of suitably protected ribonuclotides using condensing reagents ${ }^{1-5}$ and the ion-promoted oligomerization of a ribonucleoside 5'-phosphoroimidazolide. ${ }^{6,7}$ Although these are proven and reliable procedures, they inadvertently need long reaction time and yields many side products, e.g., pyrophosphates and cyclic oligonucleotides. To overcome these problems, we have recently introduced a novel strategy involving a chemical polymerization for synthesizing oligoribonucleotides directly from an unprotected ribonucleoside. ${ }^{8}$ The procedure is simple: the reaction of an unprotected ribonucleoside with tri(azol-1-yl)phosphine was followed by the in situ oxidation of the resulting phosphite with iodine and water. The polymerization reaction proceeds via a ribonucleoside 2',3'-cyclic phosphorazole, which is formed by the selective attack of tri(azol-1yl)phosphine on the 2'- and 3'-hydroxyl groups of an unprotected ribonucleoside. We have already shown the potential application of this approach to the synthesis of uridine, ${ }^{9}$ adenosine,$^{10,11}$ and cytidine ${ }^{11}$ oligonucleotides.

5-Bromouridine has been widely studied with regard to biological, ${ }^{12}$ biophysical, ${ }^{13,14}$ and photo- chemical $^{15,16}$ properties. Kyogoku, et al. showed that, in an aprotic non-polar solvent, the association constant of 1-cyclohexyl-5-bromouracil with 9-ethyladenosine was $c a$. five times larger than that of 1-cyclohexyluracil with 9-ethyladenine. ${ }^{14}$ Aqueous solvents are not favorable for the formation of the hydrogen-bonded complex between the monomers. To obtain information on the physical properties of the hydrogen-bonded complex in aqueous media, 5-bromouridine oligonucleotides are suitable. We now wish to report the application of our approach to the synthesis of 5bromouridine oligonucleotides using tri(imidazol-1yl)phosphine as the phosphorylating reagent and the interactive behavior of 5-bromouridine oligonucleotides with poly A.

\section{RESULTS AND DISCUSSION}

The reaction of 5-bromouridine with tri(imidazol-1-yl)phosphine was carried out in pyridine-tetrahydrofuran at $-78^{\circ} \mathrm{C}$ for $2 \mathrm{~h}$ and the subsequent oxidation of the resulting phosphite was achieved with iodine and water. The polymerization products were separated on Sephadex G- 25 column chromatography. Figure 1 shows the elution profile 


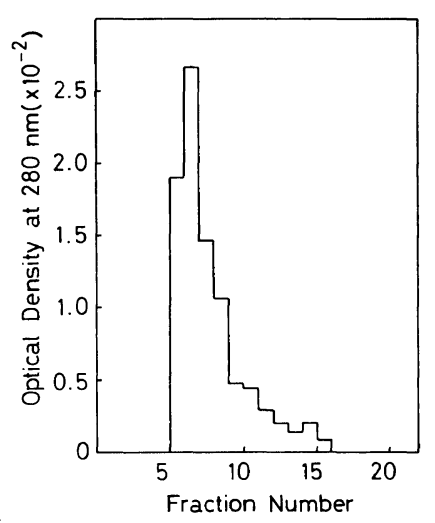

Figure 1. Sephadex G-25 column $(80 \mathrm{~cm} \times 1.6 \mathrm{~cm})$ chromatography of the polymerization products by the reaction of 5-bromouridine with tri(imidazol-1-yl)phosphine. Triethylammonium bicarbonate $(0.05 \mathrm{M}$, $\mathrm{pH} \mathrm{7.5)} \mathrm{was} \mathrm{used} \mathrm{for} \mathrm{elution} \mathrm{and} 8 \mathrm{ml}$ fractions per $6 \mathrm{~min}$ were collected.

Table I. Distribution of oligonucleotides in the fractions of Figure 1

\begin{tabular}{cccl}
\hline $\begin{array}{c}\text { Fraction } \\
\text { number }\end{array}$ & $\begin{array}{c}\text { Optical density } \\
\text { units at 280 nm }\end{array}$ & $\%$ & Identification $^{\mathrm{a}}$ \\
\hline 6 & 191.5 & 21.5 & $(\mathrm{Bp})_{5} \mathrm{~B}$ \\
7 & 265.0 & 29.7 & $(\mathrm{Bp})_{4} \mathrm{~B}$ \\
8 & 144.1 & 16.1 \\
9 & 105.8 & 11.9 & $(\mathrm{Bp})_{3} \mathrm{~B}+(\mathrm{Bp})_{4}$ \\
10 & 47.4 & 5.3 & \\
11 & 45.6 & 5.1 & $(\mathrm{Bp})_{2} \mathrm{~B}+(\mathrm{Bp})_{3}$ \\
12 & 28.5 & 3.2 \\
13 & 20.1 & 2.3 & $\mathrm{BpB}+(\mathrm{Bp})_{2}$ \\
14 & 14.6 & 1.6 & Unidentified \\
15 & 20.1 & 2.3 \\
16 & 9.6 & 1.1 & 5 -Bromouridine \\
\hline
\end{tabular}

a Product identification was carried out by enzyme and alkaline degradations of the products (see the text). "B" indicates 5-bromouridine moiety.

and the distribution of the oligonucleotides is listed in Table I. The degree of polymerization was estimated by alkaline hydrolysis ${ }^{9}$ of the products. The maximum degree of polymerization was six and the main product was pentamer under the present conditions.

In order to compare the polymerization reaction of 5-bromouridine with that of uridine, the products from 5-bromouridine and uridine were subjected to high-performance liquid chromatography (HPLC).

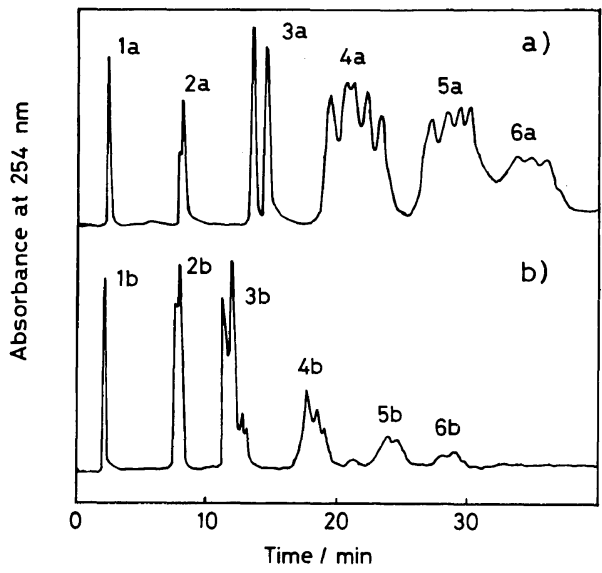

Figure 2. HPLC (Partisil $10 \mathrm{SAX}$ column) of the reaction mixture obtained from: a) the reaction of 5 bromouridine with tri(imidazol-1-yl)phosphine; b) the reaction of uridine with tri(imidazol-1-yl)phosphine.

Table II. Yields of 5-bromouridine and uridine oligonucleotides synthesized by the reaction with tri(imidazol-1-yl)phosphine under the same conditions

\begin{tabular}{|c|c|c|}
\hline Peak $^{a}$ & $\frac{\text { Yield }^{\mathrm{b}}}{\%}$ & Identification $^{c}$ \\
\hline 1a & 4.0 & 5-Bromouridine \\
\hline $2 a$ & 3.6 & Dimer, BpB \\
\hline $3 a$ & 13.1 & Trimer, $(\mathrm{Bp})_{2} \mathrm{~B}$ \\
\hline $4 a$ & 32.2 & Tetramer, $(\mathrm{Bp})_{3} \mathrm{~B}+(\mathrm{Bp})_{2}$ \\
\hline $5 \mathrm{a}$ & 27.3 & Pentamer, $(\mathrm{Bp})_{4} \mathrm{~B}+(\mathrm{Bp})_{3}$ \\
\hline $6 a$ & 19.8 & Hexamer, $(\mathrm{Bp})_{5} \mathrm{~B}+(\mathrm{Bp})_{4}$ \\
\hline $1 \mathrm{~b}$ & 11.3 & Uridine \\
\hline $2 b$ & 29.7 & Dimer, UpU \\
\hline $3 b$ & 28.5 & Trimer, $(\mathrm{Up})_{2} \mathrm{U}$ \\
\hline $4 b$ & 11.9 & Tetramer, $(\mathrm{Up})_{3} \mathrm{U}+(\mathrm{Up})_{2}$ \\
\hline $5 b$ & 9.1 & Pentamer, $(\mathrm{Up})_{4} \mathrm{U}+(\mathrm{Up})_{3}$ \\
\hline $6 \mathrm{~b}$ & 6.3 & Hexamer, $(\mathrm{Up})_{5} \mathrm{U}+(\mathrm{Up})_{4}$ \\
\hline
\end{tabular}

a Peak numbers correspond to the numbers in Figure 2.

b Yields were determined from optical densities (254 nm) for each component separated by HPLC.

c " $\mathrm{B}$ " and " $\mathrm{U}$ " indicate the 5-bromouridine and uridine moieties, respectively.

The elution profiles are shown in Figure 2. The yields of the oligoribonucleotides are summarized in Table II. 5-Bromouridine oligonucleotides highly polymerized were formed in larger quantities than 

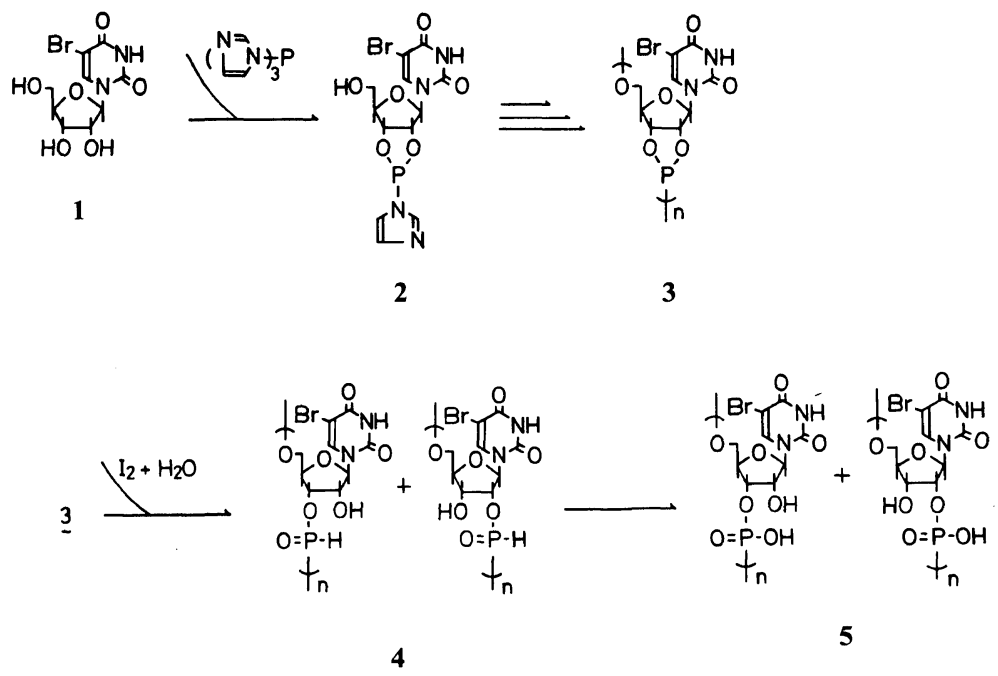

uridine oligonucleotides. In the reaction of 5-bromouridine with tri(imidazol-1-yl)phosphine, no precipitation was found. However, considerable precipitation occurred in the case of uridine oligonucleotide synthesis under the same reaction conditions. The homogeneous reaction increased the degree of polymerization.

The characreristics of the products and the type of phosphodiester linkages were investigated by degradation ${ }^{9}$ of the products, viz., degradations by snake venom phosphodiesterase, spleen phosphodiesterase, and alkaline (KOH). The oligonucleotide products, were completely hydrolyzed by both snake venom phosphodiesterase and $\mathrm{KOH}$. There were no cyclic oligonucleotides and oligonucleotides with 5 -phosphate ends. It is noteworthy that the phosphodiester linkage in 5-bromouridine oligonucleotides is composed of both $3^{\prime}, 5^{\prime}$ - and $2^{\prime}, 5^{\prime}$ linkages but not $3^{\prime}, 3^{\prime}$ - and $5^{\prime}, 5^{\prime}$-linkages. In the hydrolysis with spleen phosphodiesterase that hydrolyzes only the $3^{\prime}, 5^{\prime}$-linkage, $81 \%$ of the pentamer was resistent, indicating that this amount of the pentamer contains only $2^{\prime}, 5^{\prime}$-linkages.

These results imply the mechanism of the polymerization reaction which is initiated by the selective phosphorylation ${ }^{17}$ of the $2^{\prime}$ - and $3^{\prime}$-hydroxyl goups of 5-bromouridine 1 with tri(imidazol-1yl)phosphine. The chain elongation reaction proceeds via the resulting 5-bromouridine $2^{\prime}, 3^{\prime}$-cyclic phosphorimidazole $\mathbf{2}$ which is an active intermediate; the intermediate 2 reacts with $\mathbf{2}$ itself to give cyclic phosphite linked oligomers 3 possessing

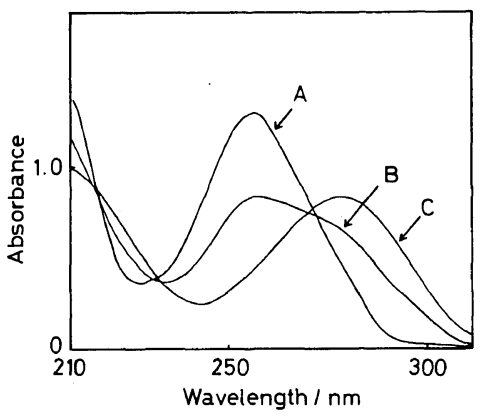

Figure 3. UV spectra of poly A, 5-bromouridine pentanucleotide, and their $1: 1(\mathrm{~mol} / \mathrm{mol})$ mixture in $0.001 \mathrm{M} \mathrm{MgCl}_{2}, 0.15 \mathrm{M} \mathrm{NaCl}$, and $0.1 \mathrm{M} \mathrm{NaHPO}_{4}(\mathrm{pH}$ 7.2) at $10^{\circ} \mathrm{C}$. a) poly $\mathrm{A}$; b) $1: 1(\mathrm{~mol} / \mathrm{mol})$ mixture of 5 bromouridine pentanucleotide and poly $\mathrm{A}$; c) 5-bromouridine pentanucleotide.

terminal phosphorimidazoles. The termination resulted from the reaction of 2 or the oligomers 3 having terminal phosphorimidazoles with the unreacted 5-bromouridine 1.

Oligomers $\mathbf{3}$ are easily oxidized with iodine and water to give 5-bromouridine oligonucleotides 5 . The oxidation reaction involves ring-opening of the cyclic phosphites and oxidation of the phosphites 4 to the phosphates $5 .{ }^{18}$ The types of phosphodiester linkages resulted from cleavage of either the 2'-O-P or the $3^{\prime}-\mathrm{O}-\mathrm{P}$ at the ring-opening step.

The interaction of 5-bromouridine pentanucleotide (5-BrU pentamer) with poly $\mathrm{A}$ was investigated by UV spectroscopy. Figure 3 shows the 


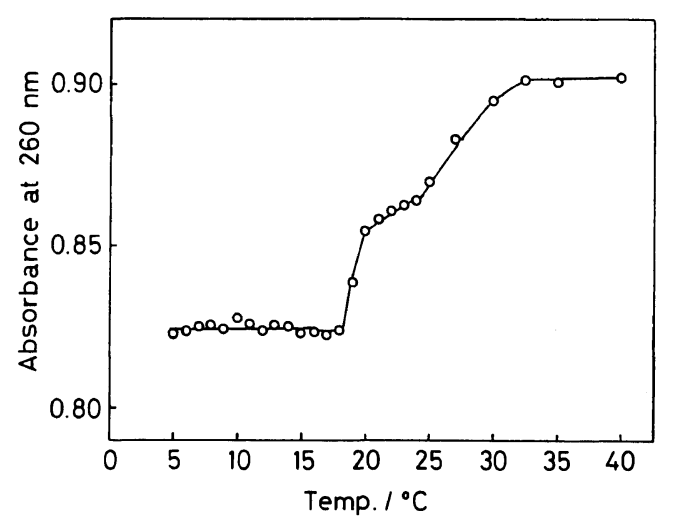

Figure 4. Temperature dependence of the UV absorption of poly $\mathrm{A}$ and 5-bromouridine pentanucleotide mixture $(1: 1, \mathrm{~mol} / \mathrm{mol})$ in $0.001 \mathrm{M} \mathrm{MgCl}_{2}, 0.15 \mathrm{M} \mathrm{NaCl}$, and $0.1 \mathrm{M} \mathrm{NaHPO}$ ( $\mathrm{pH} 7.2$ ).

UV spectra of poly A (A), a 1:1 mixture of $5-\mathrm{BrU}$ pentamer and poly $\mathrm{A}(\mathrm{B})$, and the $5-\mathrm{BrU}$ pentamer (C) at $10^{\circ} \mathrm{C}$. The UV hypochromicity down to $c a$. $8 \%$ was observed, indicating that the interaction between $5-\mathrm{BrU}$ pentamer and poly $\mathrm{A}$ occurs in the mixture. The temperature dependence of the ultraviolet absorption spectrum of the 1:1 mixture of 5$\mathrm{BrU}$ pentamer and poly $\mathrm{A}$ is shown in Figure 4. The $T_{\mathrm{m}}$ value was estimated to be $25^{\circ} \mathrm{C} .{ }^{19}$ This value is considerably high and almost the same as that of the 2poly U-oligo A (5-mer) complex. ${ }^{13}$ It was reported that the $T_{\mathrm{m}}$ value of the poly A complex with the oligo U(5-mer) was below $0^{\circ} \mathrm{C}$ under similar conditions. ${ }^{13}$ Therefore, even in an aqueous solution, the poly $\mathrm{A}-5-\mathrm{BrU}$ pentamer complex is fairly more stable than the poly A complex with the oligo $U$ of the same chain length. This stabilization of the poly A-oligo 5-BrU complex is due to the strong hydrogen bonding between adenine and 5-bromouridine bases. ${ }^{14}$ It is known that in place of thymine, 5-bromouracil can easily be incorporated into DNA at duplication process and induces mutation. ${ }^{12}$ The ability to form the strong hydrogenbonded complex may be important and related to biological process in several cases.

The present study shows a rapid and convenient synthesis of oligoribonucleotides possessing 5-bromouracil, a modified base. Owing to simplicity and convenience of this method, the procedure may be easily adapted to the synthesis of oligoribonucleotides having other biologically important modified bases.

\section{EXPẸRIMENTAL}

High-performance liquid chromatography was carried out on a Shimadzu-du Pont LC 830 instrument using a Partisil 10 SAX (ion exchange) column; the linear gradient was from $0.001 \mathrm{M} \mathrm{KH}_{2} \mathrm{PO}_{4}$ to $0.3 \mathrm{M} \mathrm{KH}_{2} \mathrm{PO}_{4}$ and contained $10 \%$ ethanol $(3 \%$ $\left.\mathrm{min}^{-1}\right)$ at $70 \mathrm{~atm}$. Ultraviolet spectra were obtained on a Union SM 401 recording spectrophotometer.

Pyridine was distilled from $p$-toluenesulfonyl chloride, redistilled from calcium hydride, and stored over 4 A molecular sieves. Tetrahydrofuran was refluxed in the presence of $\mathrm{LiAlH}_{4}$ overnight, distilled, and stored over $5 \mathrm{~A}$ molecular sieves. Phosphorus trichloride was distilled and stored in a brown ampule. 5-Bromouridine was synthesized by the reported manner. ${ }^{20}$ Imidazole (Nakarai Chemical Co.) was commercially obtained and dried in vacuo over $\mathrm{P}_{2} \mathrm{O}_{5}$ before use. Alkaline phosphatase suspended in $65 \%$ saturated aqueous ammonium sulfate $\left(1 \mathrm{mg} \mathrm{ml}^{-1}\right)$ was obtained from Sigma Chemical Co. Lyophilized snake venom phosphodiesterase $(5 \mathrm{mg})$ (Sigma Chemical Co.) and spleen phosphodiesterase (14.5 units) (P. L. Biochemical Inc.) were dissolved in $1 \mathrm{ml}$ of water. These enzyme stock solutions were used for the enzyme assay. ${ }^{9}$ Poly A (MW $\left.=10,000\right)$ was purchased from Sigma Chemical Co.

\section{Tri(imidazol-1-yl)phosphine}

The preparation of tri(imidazol-1-yl)phosphine was carried out under argon; phosphorus trichloride $(200 \mu \mathrm{l}, 2.3 \mathrm{mmol})$ was added dropwise to a solution of imidazole $(941 \mathrm{mg}, 13.8 \mathrm{mmol})$ in $16 \mathrm{ml}$ of tetrahydrofuran at $0^{\circ} \mathrm{C}$. The mixture was then stirred for $20 \mathrm{~min}$. After filtration of the imidazolium hydrochloride, the filtrate was used as a phosphorylating reagent. Tri(imidazol-1-yl)phosphine contained $c a .0 .14 \mathrm{mmol}$ in $1 \mathrm{ml}$ of the filtrate. This phosphorylating reagent was stable at least for a week in anhydrous tetrahydrofuran under argon.

\section{Synthesis of 5-Bromouridine Oligonucleotides}

5 -Bromouridine $(48.6 \mathrm{mg}, 0.14 \mathrm{mmol})$ was dried by co-evaporation with dry pyridine three times and dissolved in $0.3 \mathrm{ml}$ of pyridine and $0.2 \mathrm{ml}$ of tetrahydrofuran. To this solution, tri(imidazol-1-yl)phosphine $(0.14 \mathrm{mmol})$ in terahydrofuran $(1 \mathrm{ml})$ was added. The mixture was stirred at $-78^{\circ} \mathrm{C}$ for 
$120 \mathrm{~min}$ and then added to a solution of iodine $(35.5 \mathrm{mg}, 0.14 \mathrm{mmol})$ in $1: 1(\mathrm{v} / \mathrm{v})$ tetrahydrofuranwater $(1 \mathrm{ml})$ and stirred at $0^{\circ} \mathrm{C}$ for $30 \mathrm{~min}$. After treatment with freshly prepared aqueous sodium hydrogen sulfite $(5 \%)$, the solvent was removed in vacuo below $30^{\circ} \mathrm{C}$. The residue was dissolved in $1 \mathrm{ml}$ of water. The resulting products were analyzed by HPLC.

To obtain a large amount of the products, the solution was adjusted at $\mathrm{pH} 8$ with aqueous ammonium hydroxide and then placed on top of a Sephadex G-25 course column $(1.6 \times 80 \mathrm{~cm})$. The column was eluted with $0.05 \mathrm{M}$ triethylammonium bicarbonate $(8 \mathrm{ml}$ fractions per $6 \mathrm{~min}$ were collected). Each fraction was evaporated to dryness in vacuo below $30^{\circ} \mathrm{C}$. The residue was dissolved in water and the solution evaporated repeatedly. The remaining materials were lyophilized.

\section{Characterization of the Polymerization Products}

a) Evidence for the absence of cyclic oligonucleotides and oligonucleotides with 5'-phosphate ends. Cyclic oligonucleotides are resistant to mild alkali. ${ }^{20}$ Oligonucleotides with 5'phosphate ends are degraded by $\mathrm{KOH}^{9}$ to $\mathrm{pBp}, \mathrm{Bp}$, and $\mathrm{B}$ [from $\mathrm{p}(\mathrm{Bp})_{n} \mathrm{~B}$ ] or $\mathrm{pBp}$ and $\mathrm{Bp}$ [from $\mathrm{p}(\mathrm{Bp})_{n}$ ]. However, all the oligonucleotides obtained here were completely degraded by $\mathrm{KOH}$ to $\mathrm{Bp}$ and $\mathrm{B}$ ( $\mathrm{pBp}$ was not detected), indicating that there were no cyclic oligonucleotides and oligonucleotides with 5 '-phosphate ends in the products.

b) Degree of polymerization. To determine the degree of polymerization, the products separated by a Sephadex G-25 coarse column chromatography were hydrolyzed by $\mathrm{KOH}$; the material of the first fraction showed one peak in an ion exchange HPLC and was hydrolyzed by $\mathrm{KOH}$ to give 5-bromouridine $2^{\prime},\left(3^{\prime}\right)$-phosphate (Bp) and 5-bromouridine $(\mathrm{B})$ in a ratio $4.7: 1$. Therefore, this fraction consisted of a hexamer, $(\mathrm{Bp})_{5} \mathrm{~B}$. The material of the second fraction gave one peak in the HPLC and was hydrolyzed by $\mathrm{KOH}$ to give 5bromouridine $2^{\prime},\left(3^{\prime}\right)$-phosphate $(\mathrm{Bp})$ and 5-bromouridine (B) in a ratio $4.1: 1$. Therefore, the material of this fraction was considered to be a pentamer, $(\mathrm{Bp})_{4} \mathrm{~B}$. The materials of the third to thirteenth fractions were treated with alkaline phosphatase to remove the terminal $2^{\prime},\left(3^{\prime}\right)$-phosphate $\left[(\mathrm{Bp})_{n} \mathrm{Bp} \rightarrow(\mathrm{Bp})_{n} \mathrm{~B}\right]$. The degree of polymerization was determined by $\mathrm{KOH}$ hydrolysis of the resulting oligonucleotide $\left[(\mathrm{Bp})_{n} \mathrm{~B} \rightarrow n \mathrm{Bp}+\mathrm{B}\right]$. The material of the fifteenth and sixteenth fractions had the same retention time as 5-bromouridine.

c) Phosphodiester linkage. All the products were completely hydrolyzed by both snake venom phosphodiesterase and $\mathrm{KOH} .19 \%$ of the pentamer was hydrolyzed by spleen phosphodiesterase. Therefore, the oligonucleotide obtained here contained both $3^{\prime}, 5^{\prime}$ - and $2^{\prime}, 5^{\prime}$-linkages.

\section{Synthesis of Uridine Oligonucleotides}

A control experiment was carried out on uridine as a starting material; uridine $(35.1 \mathrm{mg}, 0.14 \mathrm{mmol})$ was dried by co-evaporation with dry pyridine three times and dissolved in $0.5 \mathrm{ml}$ of pyridinetetrahydrofuran $(3: 2, v / v)$. To this solution, tri(imidazol-1-yl)phosphine $(0.14 \mathrm{mmol})$ in $1 \mathrm{ml}$ of tetrahydrofuran was added and stirred at $-78^{\circ} \mathrm{C}$ for $120 \mathrm{~min}$. The oxidation reaction was carried out in the same manner as for 5-bromouridine oligonucleotide synthesis. After treatment with aqueous $\mathrm{NaHSO}_{3}$, the solvent was removed under reduced pressure. The residue was dissolved in water $(1 \mathrm{ml})$ and analyzed by HPLC. All the products have already been fully characterized. ${ }^{9}$

\section{Interaction of 5-Bromouridine Pentanuclaotide with Poly $A$}

The temperature dependence of the ultraviolet absorption spectrum of the 5-bromouridine pentanucleotide and poly $\mathrm{A}\left(5 \times 10^{-5} \mathrm{M}: 5 \times 10^{-5} \mathrm{M}\right)$ mixture were measured at $260 \mathrm{~nm}$ in $0.001 \mathrm{M}$ $\mathrm{MgCl}_{2}, 0.15 \mathrm{M} \mathrm{NaCl}$, and 0.1 $\mathrm{M} \mathrm{NaHPO}_{4}$ (pH 7.2). The pentamer containing both $3^{\prime}, 5^{\prime}-$ and $2^{\prime}, 5^{\prime}-$ linkages was used for the measurement.

\section{REFERENCES AND NOTES}

1. Y. Lapidot and H. G. Khorana, J. Am. Chem. Soc., 85, 3857 (1963).

2. C. Coutsogeorgopoulos and H. G. Khorana, J. Am. Chem. Soc., 86, 2926 (1964).

3. E. Ohtsuka, M. Ubasawa, S. Morioka, and M. Ikehara, J. Am. Chem. Soc., 95, 4725 (1973).

4. O. B. Straus and J. R. Fresco, J. Am. Chem. Soc., 95, 5025 (1973).

5. M. Ikehara, K. Ohsie, and E. Ohtsuka, Tetrahedron Lett., 3677 (1979).

6. H. Sawai, T. Shibata, and M. Ohno, Tetrahedron Lett., 4573 (1979).

7. H. Sawai, T. Shibata, and M. Ohno, Tetrahedron, 37, 481 (1981). 
8. T. Shimidzu, K. Yamana, A. Murakami, and K. Nakamichi, Tetrahedron Lett., 2717 (1980).

9. T. Shimidzu, K. Yamana, K. Nakamichi, and A. Murakami, J. Chem. Soc., Perkin Trans. 1, 2294 (1981).

10. T. Shimidzu, K. Yamana, K. Nakamichi, S. Maikuma, and N. Kanda, Nucleic Acids Res. Symposium Series, No. 11, 89 (1982).

11. T. Shimidzu, K. Yamana, A. Murakami, K. Nakamichi, N. Kanda, and S. Maikuma, J. Am. Chem. Soc., submitted.

12. W. Hayes, "The Genetics of Bacteria and Their Virus," Blackwell, Oxford, 1964, p 278.

13. A. M. Michelson and C. Mony, Biochim. Biophys. Acta, 149, 107 (1967).

14. H. Iwahashi and Y. Kyogoku, J. Am. Chem. Soc., 99, 7761 (1977).

15. F. Huchinson, Quart. Rev. Biophys., 6, 201 (1973).

16. I. Saito, S. Ito, and T. Matsuura, J. Am. Chem. Soc., 100, 2901 (1978).

17. The evidence for the selective phosphorylation of cisglycols including the 2',3'-hydroxyl groups of ribonucleoside with tri(imidazol-1-yl)phosphine has been appeared: T. Shimidzu, K. Yamana, N. Kanda, and S. Kitagawa, Bull. Chem. Soc. Jpn., 56, 3483 (1983)

18. After 5 min oxidation, unreacted iodine was quenched with $\mathrm{NaHSO}_{3}$. The ${ }^{31} \mathrm{P}$ NMR signal due to phosphite 4 was observed at this stage. ${ }^{10}$ The oxidation of phosphite $\mathbf{4}$ to phosphate $\mathbf{5}$ was completed within $30 \mathrm{~min}$.

19. Judging from the melting curve in Figure 4, two kinds of the hydrogen-bonded complexes were existed; at $20^{\circ} \mathrm{C}$ 2-oligo 5- $\mathrm{BrU}$-poly A complex was melted to oligo 5-BrU + oligo 5-BrU-poly $\mathrm{A}$ and at $27^{\circ} \mathrm{C}$ oligo 5-BrU-poly A complex was transformed into oligo 5-BrU+poly A. $T_{\mathrm{m}}$ value of the complex between oligo $5-\mathrm{BrU}$ and poly $\mathrm{A}$ was roughly estimated to be $25^{\circ} \mathrm{C}$. The $T_{\mathrm{m}}$ value of the complex between poly $U$ and $3^{\prime}, 5^{\prime}$-oligo $A$ was observed slightly higher than that of the complex between poly $\mathrm{U}$ and $2^{\prime}, 5^{\prime}$-oligo A. ${ }^{13}$ Therefore, the $T_{\mathrm{m}}$ value obtained here is probably not so different from that of the poly A-3',5'-oligo 5-BrU complex.

20. T. Ueda, Chem. Pharm. Bull., 8, 455 (1960).

21. D. H. Rammer, Y. Lpidot, and H. G. Khorana, $J$. Am. Chem. Soc., 85, 1989 (1963). 